\title{
A social support scale for music students in music schools, academies, and conservatories: An adaptation into Spanish and a factorial invariance study
}

\author{
Santos Orejudo ${ }^{1}$ (iD, Carlos Candela ${ }^{2}$, \\ Oscar Casanova ${ }^{3}$ and Luis Manuel Cuartero ${ }^{4}$
}

\begin{abstract}
Social support is one of the variables that exert the greatest influence on the motivation of music students, as well as on emotional aspects that affect their results. Research, however, is limited by the current scarcity of evaluation tools. This article thus presents the process of adaptation into spanish of the Social support scale. We report on the elaboration of the questionnaire's exact wording through direct and reverse translation. We subsequently present analysis of internal reliability and validity based on a sample of 668 music students in music schools and university-level music academies, aged 12-60 (mean 16.9). The study is complemented by an analysis of factorial invariance comparing secondary education and university. The results reproduce the social support factors stemming from parents and teachers; peer support is subdivided into two subcategories. Discrepancies with the original version are not so much due to the adaptation process, but can be attributed, for the most part, to differences between the sample compositions. Our results indicate that spanish music students perceive a considerable amount of social support for their music learning activities; differences stand out, however, in terms of age, gender, and educational level.

Keywords

social support scale, music students, cultural adaptation, confirmatory factor analysis, invariance
\end{abstract}

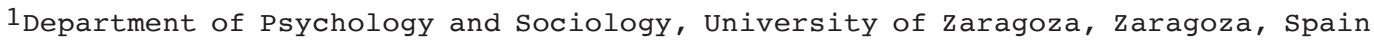
2Department of Health Psychology, University Miguel Hernández, Elche, Spain

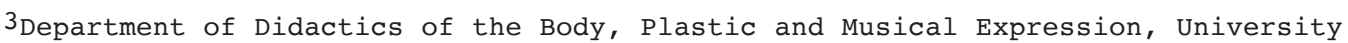
of Zaragoza, Zaragoza, Spain

${ }^{4}$ Professional Conservatory of Music of Alcañiz, Government of Aragon, Alcañiz, Spain

Corresponding author:

Santos Orejudo, Department of Psychology and Sociology, University of Zaragoza, Zaragoza, Spain. Email: sorejudo@unizar.es
} 
In order to grasp the factors that can play a role in young people's motivation for learning as well as in their academic results, an analysis of teaching procedures and academic performance does not suffice; it is also necessary to take the students' psychological and social environment into account (Gaertner \& Mcclarty, 2015; Song, Bong, Lee, \& Kim, 2015). Such factors are especially relevant in the case of music students. When seeking to address those social and psychological dimensions, one of the variables that seems to play a crucial role is social support (Hallam et al., 2016; Lehmann \& Kristensen, 2014), which can stem from individuals who are described by some authors as "persons in the shadow" (Gruber, Lehtinen, Palonen, \& Degner, 2008).

Social support can be understood as the relative presence or absence of psychological sup- port stemming from significant third parties (Caplan, 1974) who help satisfy the student's basic need of interaction with others. Cobb (1976) defines the construct of social support as the information which enables people to feel that someone is taking care of them, has concern for their needs, loves them, appreciates them, and values them; they need to feel that they form part of a communication network where they can fulfill mutual obligations. Moreover, social support is generally defined as the existence or availability of people in whom we can trust; people who let us know that we matter to them, that they cherish and love us (Sarason, Pierce, \& Sarason, 1990). The concept of social support is characterized by its multidimensionality. Our investigation on the subject of social support takes the following principal dimensions into account: the different types of social support and the agents from whom such support can stem, along with the way that support is evaluated-be it in the form of available resources, or in the manner in which the latter are subjectively perceived.

Several authors have posited the different types of social support that can be analyzed. In the context of music education, Creech (2009) provides one sole theoretical model to describe the attitude of parents toward their children's musical education. His model takes three types of social support into account: behavioral support, cognitive-intellectual support, and personal support. Behavioral support is the kind of support in which the parents play a role similar to that of a professor, but at home: assistance with studies, helping the young person organize his or her work, and so on. Cognitive or intellectual support consists in planning all types of activities that can stimulate and help the young person develop musical abilities: attending concerts, listening to recordings, or participating in extracurricular musical activities. Personal support means the kind of help that encourages the young person to formulate expectations and estab- lish goals, while understanding and motivating the child regarding the successes he or she is able to achieve.

The different agents capable of providing social support have likewise been analyzed. Parents, the teacher of the instrument, other teachers, friends, colleagues, and siblings have all been mentioned as potential sources of support, although not all of them have the same rele- vance in the achievement of academic success, or as sources of different types of support (Nogaj

\& Ossowski, 2015). Lehmann and Kristensen (2014) suggest that parents, teachers, and peers can be regarded as the three most influential social agents within the context of music educa- tion: those same agents are the ones listed as sources of social support in the social support scale proposed by Ryan, Boulton, O'Neill, and Sloboda (2000), which is the tool we have adapted to a Spanish context in this article. Sichivitsa (2007) coincides with these suggestions when she designates three sources of support as the ones which play the most relevant role in fomenting musical motivation; she also mentions that there can be a relation between parental support and teacher support, and that the parents' degree of involvement with music can be a key factor in creating that support. This latter aspect, the parents' relation with music, is regarded by Jeppsson and Lindgren (2018) as a crucial element that transfers a great amount 
of "cultural baggage" to the child, thus become a key for the child to achieve success in the musical domain.

Several studies, from both an empirical and a theoretical perspective, have ascertained the relevance of social support for certain achievements in the musical domain. Thus, for instance, Moore, Burland, and Davidson (2003) found that, among other factors, the teacher's friend- liness as perceived by the student is a variable that can help predict progress in musical trainingalong with two further factors: (1) being able to count on maternal support during the first stages of training and (2) having "pushy," demanding professors in the more advanced stages. More recently, in a study of adolescent Polish music pupils, Nogaj and Ossowski (2015) found a significant relation between the pupils' academic success and the degree of social sup- port they had received; the authors ascertained that such support mainly comes from parents and from music instrument teachers. To a greater degree than evaluative or instrumental sup- port, the most relevant type of support in all of these sources is emotional support. Sichivitsa (2007) estimates that parental support is a major factor in forming a student's musical selfconcept. Further revisions and theoretical approaches can be found in Creech and Hallam (2003), McPherson (2009), and Lehmann and Kristensen (2014).

Certain issues that emerge along these lines are related with the manner in which different types of support adapt progressively to the music students' own needs; the importance of differ- ent types of support varies widely in the course of many years of musical training, and student expectations vary depending on the kind of support. Thus, for example, Bloom (1985) points out that the most suitable kind of pedagogue is a kind, friendly teacher in the first years, then, in the intermediate years, a teacher who focuses on developing the student's abilities, and, toward the end of training, a professor who is truly involved, as a colleague, in actively support- ing the student's professional career. Moore et al. (2003) supply further evidence along these lines. Family support has been clearly identified as an extremely important factor in the first stages of musical training (Davidson, Howe, Moore, \& Sloboda, 1996; Margiotta, 2011); less data are available, however, on the subject of the importance of family support during the period of advanced training.

In order to investigate the role of social support in the area of musical education, we need to have valid and reliable measurement tools at our disposal. In this field, however, they are quite scarce. Our review of the subject has only yielded two extant scales: the Social support Scale by Ryan et al. (2000) and the Social support Scale by Gluska (2011). Both scales have good psy- chometric properties and are similar in terms of design. They gather social support data in rela- tion to three different sources: parents, teachers, and peers. Gluska (2011), however, differentiates between social support on the part of the instrument teacher and that provided by other teachers. For this article, we have adapted the scale conceived by Ryan et al. (2000), since it is written in a language more accessible to us than that used by Gluska (English instead of Romanian); at the same time, it has been validated for a much wider sample that includes younger subjects who are closer in age to those featured in our current study. The Ryan scale bears upon aspects related to support in the learning of an instrument as well as with support associated with evaluation of achievements.

The proposal we present here increases the validation prospects of the scale conceived by Ryan et al. (2000) by extending the age group to include pupils from the age of 12 onward. Our sample included pupils with different goals and expectations, ranging from those who wish to pursue a professional career and are enrolled in university-level music conservatories and academies to those who are merely undergoing music training as a hobby, or as a preliminary stage to professional studies: in spain, the latter are enrolled in music schools that are called conservatorios profesionales. 
Materials and methods

Participants

Participants in this study were 668 music students enrolled in six spanish institutions of musi- cal learning: four of those institutions confer a music school diploma, while the two others confer a university-level diploma. In spain, intermediate-level music schools (conservatorios profesionales) are more widespread than university-level music academies, and they attract students with profiles that are more diverse. They range from those who are studying with the goal of continuing on a university level (in conservatorios superiores) and who want to become music professionals, to others who are merely learning to play an instrument as part of their overall education, as an extracurricular activity, or as a mere pastime. Out of a total of 668 partici- pants, $70.9 \%$ of these sample subjects (Age: $M=16.90, S D=5.33$, $71.3 \%$ were 17 years old or younger) were enrolled in secondary-level music schools (conservatorios profesionales), and 29.2\% (Age: $M=21.44, S D=4.58$, $98.4 \%$ were 18 years or older) were enrolled in university- level music academies (conservatorios superiores). Among the sample subjects, 47\% were male and 53\% were female. No significant differences of gender distribution between the secondary school level and the university level were ascertained $\left(\chi^{2}=\right.$ $0.514, p=.468)$. Boys generally tended to be older $(M=19.17, S D=6.81)$ than girls $(M=17.43, S D=3.88)$. The sample was made up of various instrumental specialties: keyboard $(n=113)$, strings $(n=231)$, brass $(n=$ 99), woodwind ( $n=172)$, percussion $(n=29)$, voice $(n=12)$, conducting ( $n=$ $2)$, composi- tion $(n=1)$, and contemporary music $(n=8)$.

The academies were chosen according to accessibility. The institutions we selected were located in three different spanish regions where members of our team were participating in collaborative projects designed to improve students' musical training, either by orienting the teachers or working together directly with the students.

After a period of 3 months had elapsed, a subsample of 75 students completed the same questionnaire in order to generate data regarding its stability over time. That subsample was extracted from the initial sample, once more according to the availability criterion. We thus re- contacted two of the six institutions that had originally participated in the study: a music school (36 participants) and a university-level conservatory (38 participants). We gathered data from those students who were available in class on the days when our research team visited the schools.

Variables and instruments

The Social support scale proposed by Ryan et al. (2000) was designed to evaluate the level of social support perceived by music students. It measures that support through a series of inde- pendent scales corresponding to each of the social agents: parents, professors, and peers, cor- responding with 12 , 9, and 10 items, respectively, measured on a 7-point Likert-type-style scale (from $1=$ not very much to $7=a$ lot). The items of the equivalent version in English are shown in Table 2 .

In order to elaborate the spanish language version of the Social support Scale, we imple- mented a series of procedures (Abad, Olea, Ponsoda, \& García, 2011; Carretero \& Pérez, 2007; Muñiz, Elosua, \& Hambleton, 2013). The four members of our research team started by trans- lating a first version of the scale from English to Spanish which maintained all 31 items of the original. On the basis of that translated version, we carried out a pilot test on a sample of 100 music school students in order to guarantee the items' comprehensibility as well as their initial 
internal reliability, while ensuring at the same time that the test results would not produce widely varying results when compared with the original.

That Spanish version of the questionnaire (see Supplemental Materials online) was there- upon submitted to the process of reverse translation by experts, as authors recommended. Two bilingual experts in Spanish and Englisha psychologist and a musician-proceeded to trans- late the Spanish version back into English, after which they compared the new English version with the original by Ryan et al. (2000). As a final task, they were asked to evaluate the degree of agreement among the two scales: reverse-translated English and original English. As a con- sequence of their judgments, two items were modified.

We obtained a further indicator to validate the scale: the degree of the family's involvement with music and music education. The relation of each parent with music was taken into account: (1) passive music fans (who listen to or attend concerts), (2) amateurs (who play a music instrument as a pastime), (3) professional musicians or music teachers, and (4) individuals who are professional musicians and teachers at the same time. As a result of that informa- tion, we grouped the students into two entirely separate categories: (1) those with musician parents (when one of the two parents plays an instrument, is a professional musician, or teaches music) and (2) those with parents who are merely passive consumers of music (when- ever the above categories did not apply).

\section{Procedure}

Data collection procedure. After having received an affirmative response from the above-cited institutions of musical learning, we proceeded to gather the data in person, on the premises. The research team visited the academies in order to operate in situ, with the exception of the Conservatories of Pamplona and Elche, where a local professor was entrusted with the task of administering and gathering the questionnaires. Students participated on a voluntary, anony- mous basis. The authorization for the research project was obtained from the Doctorate in Edu- cation Program of the University of Zaragoza.

Statistical procedure. We carried out an initial analysis of the items with mean and standard deviation values, along with skewness and kurtosis indices. We also obtained internal consist- ency results through Cronbach's Alpha and corrected item-total correlations. All of these are good preliminary options prior to subsequent levels of analysis (Lloret, Ferreres, Hernández, \& Tomás, 2014). In order to obtain the factorial structure of the set of results, we ran an explora- tory procedure (EFA) and a confirmatory analysis (CFA) on two randomly generated independ- ent subsamples. Such an approach is justified, even when current intermediate alternatives between both options exist (such as environmental scanning electron microscope (ESEM) anal- ysis), provided that the sample is sufficiently large and can be randomly subdivided in order to apply the traditional validation procedure (Byrne, 2012; Lloret et al., 2014). This first portion of the analysis was carried out with the SPSS statistical app in its 22.00 version. The software generates a variance-covariance matrix and is adequate for Likert-style scales of at least 7 points, as in this case, and when items have normal distribution, which is the case for all 31 items in the test except for three.

In order to apply CFA to the second subsample, we used the M-plus program. It is a robust procedure capable of estimating maximum likelihood, and is not affected if the assumption of multivariate normal distribution is not met. Finally, to carry out a study of factorial invariance with the purpose of following the recommendations proposed by Byrne (2012), we first estab- lished the model in each one of the groups, after which we proceeded to apply a global 
Table 1. Internal consistency analysis (Cronbach's $\alpha$ ).

\begin{tabular}{|c|c|c|c|c|c|c|c|c|}
\hline \multirow[b]{2}{*}{ Scale } & \multirow[b]{2}{*}{$\begin{array}{l}\text { No. } \\
\text { of } \\
i+\infty m\end{array}$} & \multicolumn{4}{|c|}{ Initial questionnaire } & \multicolumn{3}{|c|}{ Revised questionnaire } \\
\hline & & $\begin{array}{l}\text { Tota } \\
1 \\
\text { camn }\end{array}$ & $\begin{array}{l}\text { Conserv. } \\
\text { professi } \\
\end{array}$ & $\begin{array}{l}\text { Conser } \\
\text { V. } \\
\text { • }\end{array}$ & $\begin{array}{l}\text { No. } \\
\text { of } \\
i+\infty m\end{array}$ & $\begin{array}{l}\text { Total } \\
\text { sample }\end{array}$ & $\begin{array}{l}\text { Conserv. } \\
\text { professi } \\
\end{array}$ & $\begin{array}{l}\text { Conser } \\
V \text {. }\end{array}$ \\
\hline \multirow{2}{*}{$\begin{array}{l}\text { Paren } \\
\text { tal }\end{array}$} & 12 & .836 & .829 & .843 & 11 & .849 & .840 & .866 \\
\hline & & $\begin{array}{l}\text { Items } \\
2,\end{array}$ & Item 2 & Item 2 & & $\begin{array}{l}\text { witho } \\
\text { ut }\end{array}$ & $\begin{array}{l}\text { witho } \\
\text { ut }\end{array}$ & $\begin{array}{l}\text { witho } \\
\text { ut }\end{array}$ \\
\hline $\begin{array}{l}\text { Teach } \\
\text { er }\end{array}$ & 9 & $.86 \overline{6}$ & .869 & .867 & 9 & & & \\
\hline \multirow[t]{6}{*}{$\begin{array}{l}\text { Peer } \\
\text { support }\end{array}$} & 10 & $\begin{array}{l}.859 \\
\text { Item } 2\end{array}$ & $\begin{array}{l}.855 \\
\text { Item } 2\end{array}$ & $\begin{array}{l}.870 \\
\text { Items } \\
2\end{array}$ & 8 & .866 & .879 & .862 \\
\hline & & & & & & $\begin{array}{l}\text { witho } \\
\text { ut }\end{array}$ & $\begin{array}{l}\text { witho } \\
\text { ut }\end{array}$ & $\begin{array}{l}\text { witho } \\
\text { ut }\end{array}$ \\
\hline & & & & & & .868 & .864 & .886 \\
\hline & & & & & & witho & without & witho \\
\hline & & & & & & & Items 2 & \\
\hline & & & & & & Items & and 3 & Items \\
\hline Peer & & & & & 5 & .785 & .770 & .819 \\
\hline $\begin{array}{l}\text { Peer } \\
\text { sunnort } 2\end{array}$ & & & & & 3 & .935 & .934 & .938 \\
\hline
\end{tabular}

adjustment. Following Elosúa (2005), the levels of invariance we took into consideration refer to configural invariance as well as to metric and strict invariance.

\section{Results}

The initial analysis of the items shows the following: the ones which are associated with family support have high median values ranging from 5.50 to 6.47 for all items except for Items 2 ("help you to play an instrument?") and 5 ("help you to play an instrument?") (which do not surpass 3.46 and 3.97, respectively). The median values attained in teacher support items are also high, but to a lesser degree: they average from 4.86 to 6.40, whereby none of the item scores is exceedingly distant from the others. Values associated with peer support display a pat- tern similar to family support items: medium-high values ranging from 4.35 to 5.26 hold for most items, except for Items 2 ("help you to play an instrument?") and 3 ("want you to play an instrument more than other activities you do?"), which do not follow the same tendency and present much lower scores ranging from 2.65 to 3.67 .

Table 1 presents the results of the internal consistency of the subscales, on a global level as well as divided into educational levels. The parent support scale has good initial internal con- sistency $(\alpha=.836)$, and it improves by eliminating Items 2 ("help you to play an instrument?"), 3 ("want you to pass your exams?"), and 5 ("help you to play an instrument?") ( $\alpha=$ .849): Item 3 had a much higher mean score and less variance than the others; Item 2 stands out for hav- ing a much lower score and a lower corrected itemtotal correlation than the rest, even though the latter exceeds . 30 .

The teacher support scale has good internal consistency $(\alpha=.866)$, and its results cannot be improved by eliminating any specific item. The mean of item values, lying between 4.86 and 6.41 , denotes that the students also perceive that they receive support from their teachers. The corrected item-total correlation exceeds .53 on all items. 
As a third major group, the peer support values display a high internal consistency $(\alpha=.859)$. This group improves by eliminating Item 2 ("help you to play an instrument?"). The latter item, with a content similar to Item 2 in parental support, has a lower value (2.62); the same applies to Item 3, "want you to play an instrument more than other activities you do?" (3.64). Their corrected item-total correlations are lower than those of the other items, lying between .345 and .446. By successively omitting Items 2 and 3 , internal consistency improved considerably, leading to an ultimate value of $\alpha=.868$.

The EFA and CFA results are featured in supplemental Materials. The conclusions drawn from them are in line with the analysis of the items commented above regarding the parent and teacher support scale. Those scales' items group together (Table 2), except for the three previ- ously mentioned parent support items: the result is thus a scale with nine items for parent sup- port and 10 items for teacher support.

However, the peer support scale delivers a novel result: the two procedures (EFA and CFA) support a division of the items in this group into two subgroups. The first factor groups five items together $(\alpha=.785)$ : they are related to peer support for musical tasks and activities. The second factor groups three items together $(\alpha=.935)$, referring to peer support in the face of taunts and insults.

Invariance analysis by educational levels is likewise presented in Supplemental Materials; the pattern we have elucidated shows a high degree of stability, since invariance analysis repro- duces the four-factor structure on both levels. Only three items present certain variations.

When we compare the different types of support perceived by the students, we can confirm that they find their most important source of support in their parents ( 6.03 on a scale from 1 to 7), followed by peer support in the face of taunts and insults (5.15) and by peer support for musical tasks (4.99) together with teacher support (4.96), without statistically significant differences between the last two $(t=0.469, p=.639)$.

The correlation pattern between the sources of social support perceived by

the students is of great relevance. We find a high correlation $(r=.525)$

between peer support for musical tasks and activities (F1) and peer support in the face of taunts and insults (F2). However, parent sup- port has significant correlations, but to a lesser degree, with teacher support ( $r=$ $.334)$ as well as with peer support of musical tasks $(r=.308)$. The remaining correlations, although statisti- cally significant, have lower scores. Thus, parent and peer support in the face of taunts and insults has a value of $r=.197$, teacher and peer support for musical tasks has a value of $r=$ .169, and teacher and peer support in the face of taunts and insults has a value of $r=.104$. This correlation pattern, observed across the entire

sample, yields some differences if we analyze it by age groups; the greatest

differences appear in the group of 16- to 17-year-olds. In their group, the correlation between peer support of musical tasks (F1) and peer support in the face of taunts and insults (F2) descends to $r=.360$. The correlation

between parent support and peer support remains above $0.30(r=.308)$, but the correlation between parent support and peer support F1 descends to .200 . The remaining correlations are no longer statistically

significant.

Table 3 displays the ANOVA results of a factor with which we analyzed the tool's capacity to detect differences among variables in cases where such differences would normally be expected, thereby searching for additional evidence of validity. Thus, we found differences in the Parent support scale $\left(F(1,607)=26.863, p<.001, \eta^{2}=.042\right)$ depending on whether the parents are mere passive music consumers $(M=53.11)$ or have a closer active connection with music $(M=56.44)$. Age-related differences also surfaced $\left(F(3,638)=4.902, p=.002, \eta^{2}=.023\right)$, whereby the group of younger students, ages 11-15, reported a greater amount of support from parents ( $M$ $=56.20$ ) than the rest. Finally, university-level students perceive a greater 